\title{
Demographic Characteristics and Anatomical Location of Primary Spinal Cord Tumour Patients operated at a Referral Neuroscience Hospital in Dhaka City
}

\author{
Md. Shafiul Alam¹, Kaisar Haroon², Md. Abdullah Alamgir ${ }^{3}$, Muhammad Tanvir Ashraf $^{4}$, \\ Monsur Ahmed ${ }^{5}$, Kazi Hafiz Uddin ${ }^{6}$
}

${ }^{1}$ Associate Professor, Department of Gamma Knife, National Institute of Neurosciences \& Hospital, Dhaka, Bangladesh; ${ }^{2}$ Assistant Professor, Department of Neurosurgery, National Institute of Neurosciences \& Hospital, Dhaka, Bangladesh; ${ }^{3}$ Associate Professor, Department of Neurosurgery, National Institute of Neurosciences \& Hospital, Dhaka, Bangladesh; ${ }^{4}$ Junior Consultant, Department of Orthopaedics, National Institute of Trauma, Orthopaedics \& Rehabilitation, Dhaka, Bangladesh; ${ }^{5}$ Assistant Professor, Department of Neurosurgery, National Institute of Neurosciences \& Hospital, Dhaka, Bangladesh; ${ }^{6}$ Assistant Professor, Department of Neurosurgery, National Institute of Neurosciences \& Hospital, Dhaka, Bangladesh

[Received: 1 October 2019; Accepted: 12 November 2019; Published: 1 January 2020]

\begin{abstract}
Background: Spinal tumor can occur in different anatomical location. Objective: The purpose of the present study was to see the demographic characteristics and anatomical location of spinal tumour. Methodology: This descriptive cross sectional study was conducted in the Department of Neurosurgery at National Institute of Neurosciences \& Hospital, Dhaka, Bangladesh from January 2016 to December 2019 for a period of around 04 (four) years. Patients presented with spinal tumor were selected as study population. The demographics characteristics were evaluated among all the patients. Patients were examined by MRI for the detection of anatomical location of the tumor. Result: A total number of 57 spinal tumor cases were recruited for this study. The mean age with SD of the study population was $38.7 \pm 13.24$ years. The male and female ratio was 1.34:1 Most of the spinal tumor were found in the thoracic region which was $29(50.9 \%)$ cases followed by lumbar region which was $20(35.1 \%)$ cases. Spinal tumor in cervical region was found in only $5(8.8 \%)$ cases. Conclusion: In conclusion adult middle age male patients are the most commonly suffering from spinal tumor which are mostly located in the thoracic region. [Journal of National Institute of Neurosciences Bangladesh, 2020;6(1): 15-18]
\end{abstract}

Keywords: : Demographic characteristics; anatomical location; spinal tumour

Correspondence: Dr. Md. ShafiulAlam, Associate Professor, Department of Gamma Knife, National Institute of Neurosciences \& Hospital, Dhaka, Bangladesh; Email: dr_chapal@hotmail.com; Cell No. : 01711567358

Conflict of interest: There is no financial conflict of interest relevant to this paper to disclose.

Funding agency: This research project was not funded by any group or any institution.

Contribution to authors: Alam MS, Haroon K have contributed from the protocol preparation, data collection up to report writing. Manuscript writing and revision have been performed by Alamgir MA, Ashraf MT, Ahmed M, Uddin KH.

How to cite this article: Alam MS, Haroon K, Alamgir MA, Ashraf MT. Demographic Characteristics and Anatomical Location of Primary Spinal Cord Tumour Patients operated at a Referral Neuroscience Hospital in Dhaka City. J NatlInstNeurosci Bangladesh, 2020;6(1): 15-18

Copyright: (C2020. Alam et al. Published by Journal of National Institute of Neurosciences Bangladesh. This article is published under the Creative Commons CC BY-NC License (https://creativecommons.org/licenses/by-nc/4.0/). This license permits use, distribution and reproduction in any medium, provided the original work is properly cited, and is not used for commercial purposes.

\section{Introduction}

Primary spinal cord tumours are the tumours that originate from the spinal cord, its coverings or surrounding soft tissues except bony elements. Primary spinal cord tumors are one of the rarest categories of tumors, representing about $4-16 \%$ of all tumors arising from the central nervous systems (CNS) according to previous reports ${ }^{1-3}$. Because of variation in population sizes studied and classification of tumors, the frequencies of different spinal cord tumors vary among these reports. Although there are many reports on the epidemiology of all CNS tumors (including brain and spinal cord or brain only), there are less reports focusing upon epidemiology of spinal cord tumors alone $e^{4-5}$. The overall incidence is about $.74-2.5$ per 100000 persons $^{6}$. The hospital-based incidences of various tumors, in the occurrence of age and gender were revealed in the analysis of tumors of the spinal cord, nerves, meninges. This present study was 
undertaken to see the demographic characteristics and anatomical location of spinal tumour.

\section{Methodology}

This descriptive cross sectional study was conducted in the Department of Neurosurgery at National Institute of Neurosciences \& Hospital, Dhaka, Bangladesh from January 2016 to December 2019 for a period of 4 (four) years. Patients presented with spinal tumor at any age with both sexes were selected as study population. The demographics characteristics like age and gender were recorded among all the patients. Patients were examined by MRI for the detection of anatomical location of the tumor. The locations of involvement were divided into 4 levels which were cervical, thoracic, lumbar, and lumbosacral regions. The patients with hematologic and bone malignancy were excluded from this present study. The data were analyzed by using SPSS and reported with descriptive statistics. Categorical variables were expressed as frequency and percentage with the range of the data set. However, the continuous variables were expressed as mean with standard deviation when these data set were normally distributed. The present study was approved by local ethical committee.

\section{Results}

A total number of 57 spinal tumor cases were recruited for this study. The mean age with SD of the study population was $38.7 \pm 13.24$ years with the range of 14 to 70 years.Most of the patients were in the age group of 40 to 60 years of age group which was $27(47.4 \%)$ cases followed by 20 to 40 years of age group and less than 20 years which were $22(38.6 \%)$ cases and $6(10.5 \%)$ cases respectively. Only 2 cases were in the age group of more than 60 years of age group (Table $1)$.

Table 1: Age Distribution among Study Population $(\mathrm{n}=57)$

\begin{tabular}{lcc}
\hline Age Group & Frequency & Percent \\
\hline Less than 20 Years & 6 & 10.5 \\
20 to 40 Years & 22 & 38.6 \\
40 to 60 Years & 27 & 47.4 \\
More than 60 Years & 2 & 3.5 \\
Total & $\mathbf{5 7}$ & $\mathbf{1 0 0 . 0}$ \\
\hline
\end{tabular}

Male was predominant than female which was $33(57.9 \%)$ cases and $24(42.1 \%)$ cases respectively. The male and female ratio was 1.34:1 (Table 2).
Table 2: Gender Distribution among the Study Population

\begin{tabular}{lcc}
\hline Gender & Frequency & Percent \\
\hline Male & 33 & 57.9 \\
Female & 24 & 42.1 \\
Total & $\mathbf{5 7}$ & $\mathbf{1 0 0 . 0}$ \\
\hline
\end{tabular}

Most of the spinal tumor were found in the thoracic region which was 29(50.9\%) cases followed by lumbar region which was $20(35.1 \%)$ cases. Spinal tumor in cervical region was found in only $5(8.8 \%)$ cases. 3 (5.3\%) were found in Lumbosacral region (Table 3).

Table 3: Anatomical Location of Spinal Tumor among study Population

\begin{tabular}{lcc}
\hline Location & Frequency & Percent \\
\hline Cervical Region & 5 & 8.8 \\
Thoracic Region & 29 & 50.9 \\
Lumbar Region & 20 & 35.1 \\
Lumbosacral Region & 3 & 5.3 \\
Total & $\mathbf{5 7}$ & $\mathbf{1 0 0 . 0}$ \\
\hline
\end{tabular}

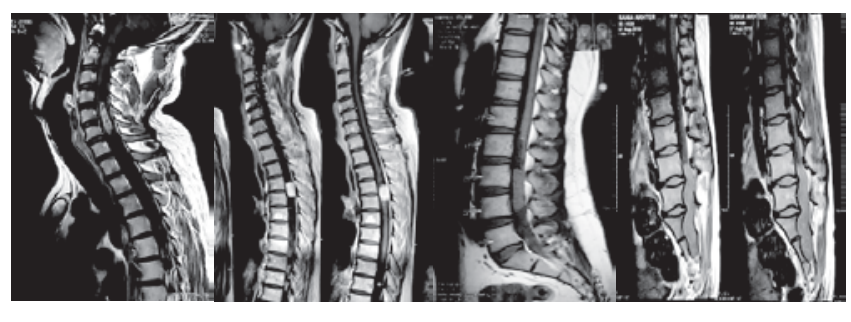

(a)

(b)

(c)

(d)

Figure 1: MRI of the spine showing spinal cord tumour at (a) cervical, (b) Dorsal, (c) Lumber and (d) Lumbosacral region.

\section{Discussion}

Space occupying lesions in the spinal canal cause compression of the structures with resultant neurological deficits? ${ }^{7}$. Rapidly growing lesions cause severe loss of function as there is no time for the spinal cord to adjust itself. The presence of a tumor interferes with the normal movements of the cord, which occur during movements of the spinal column. Such impairment contributes to cord damage ${ }^{8}$. In long standing tumors, there may be gliosis in the spinal cord due to ischemia and recovery may be incomplete despite complete removal of the tumor. Initial assessment of the patient with a primary spinal tumor requires meticulous application of common clinical tools including a detailed history and clinical examination'. Clinical presentation usually relates to pain, varying degrees of motor sensory deficits as well as bowel bladder symptoms in some, which may be due 
to either mass effect or neurological compression ${ }^{10}$. A total number of 57 spinal tumor cases were recruited for this study. The mean age with SD of the study population was $38.7 \pm 13.24$ years with the range of 14 to 70 years. Most of the patients were in the age group of 40 to 60 years of age group which was $27(47.4 \%)$ cases followed by 20 to 40 years of age group and less than 20 years which were $22(38.6 \%)$ cases and $6(10.5 \%)$ cases respectively. Only 2 cases were in the age group of more than 60 years of age group. Similar results have been reported by Hiranoet $\mathrm{a}^{11}$ and have been analyzed on 678 patients with primary spinal cord tumors who are surgically treated. The mean age at surgery is 52.4 years with the range of 2 months to 92 years. When stratified by patient age in 10-year intervals, the patient groups aged 50 to 59 years and 60 to 69 years encompassed the largest number of patients with primary spinal cord tumors; only $4.1 \%$ of patients are under the 20 years of age. Hiranoet $\mathrm{al}^{11}$ have stated that the mean age of presentation of patients with IDEM tumors is 35.88 and those having IMSCT are 25.79 and in extradural tumors was 30.77 . The mean age of IMSCTs in these series is less as compared to that of the western world; however, it is comparable to Indian reports. This is due to the presence of significant number of pediatric patients in this subgroup.

Male is predominant than female which is $33(57.9 \%)$ cases and 24(42.1\%) cases respectively. The male and female ratio is $1.34: 1$. Therefore, this is a clear evident that male is most commonly suffering from spinal tumor.Similarly, Hiranoet a ${ }^{11}$ have stated that of the 678 patients, $55.6 \%$ are male and $44.4 \%$ are female which is consistent with the present study result. According to previous studies, the male and female ratios for patients with primary spinal cord tumors vary among countries from $40.0 \%$ male and $60.0 \%$ female in the USA ${ }^{12}$; furthermore, $60.3 \%$ male and $39.7 \%$ female is found in China ${ }^{13}$. In Asian countries spinal cord tumors predominantly occur in men, whereas in non-Asian countries they predominantly occur in women ${ }^{11}$. Furthermore, several studies have reported that spinal meningioma occurs much more frequently in women than in $\operatorname{men}^{7,9,14}$. The female preponderance for spinal meningiomas is universal ${ }^{11}$. As Engelhard et $\mathrm{al}^{9}$ pointed out the female preponderance in meningiomas alone is enough to change male and female ratios for entire spinal cord tumor series (in non-Asian countries). However, in Asian countries, where the frequencies of spinal meningiomas overall are lower than in non-Asian countries, the male and female ratio for an entire series might not be affected by the male and female ratio for meningiomas. Engelhard et $\mathrm{al}^{9}$ have pointed out that there is a slight male preponderance for primary intraspinal tumors. There is a male preponderance in schwannomas, ependymomas, hemangiomas, hemangioblastomas, neurofibromas, malignant lymphomas, and lipomas ${ }^{15}$. The literature indicates that in western populations, the primary spinal tumors occur more frequently in females, whereas Asian studies show a slight male preponderance ${ }^{16}$. Similar male to female ratio has been reported by other studies from India ${ }^{8}$.

\section{Conclusion}

In conclusion adult middle age patients are most commonly suffering from the spinal cord tumour. Furthermore, male is predominant than female. Interestingly the thoracic and lumbar region are the most common location of spinal tumor. Few cases are found in the cervical region. Further large scale study should be performed to see the real scenario.

\section{References}

1. Char G, Cross JN, Persaud V. Tumors of the central-nervoussystem analysis of 476 cases observed at the UniversityHospital-of-the-West-Indies. West Indian Med J. 1987;36: 140-149

2. Cheng MK. Spinal cord tumors in the People's Republic of China: a statistical review. Neurosurgery. 1982;10:22-24

3. Chi JG, Khang SK. Central nervous system tumors among Koreans-a statistical study on 697 cases. J Korean Med Sci. 1989:4:77-90

4. Elia-Pasquet S, Provost D, Jaffre A, Loiseau H, Vital A, Kantor G, Maire JP, Dautheribes M, Darrouzet V, Dartigues JF, Brochard $\mathrm{P}$, Baldi I. Incidence of central nervous system tumors in Gironde, France. Neuroepidemiology. 2004;23:110-117

5. Fogelholm R, Uutela T, Murros K. Epidemiology of central nervous system neoplasms. A regional survey in Central Finland. ActaNeurol Scand. 1984;69:129-136

6. Louis DN, Ohgaki H, Wiestler OD, Cavenee WK, Burger PC, Jouvet A, et al. The 2007 WHO classification of tumours of the central nervous system. ActaNeuropathol. 2007;114:97-109

7. Milano MT, Johnson MD, Sul J, Mohile NA, Korones DN, Okunieff P, Walter KA. Primary spinal cord glioma: a Surveillance, Epidemiology, and End Results database study. Journal of neuro-oncology. 2010;98(1):83-92

8. Shrivastava RK, Epstein FJ, Perin NI, Post KD, Jallo GI. Intramedullary spinal cord tumors in patients older than 50 years of age: management and outcome analysis. J Neurosurg Spine. 2005;2:249-255

9. Engelhard HH, Villano JL, Porter KR, Stewart AK, Barua M, Barker FG, Newton HB. Clinical presentation, histology, and treatment in 430 patients with primary tumors of the spinal cord, spinal meninges, or caudaequina. J Neurosurg Spine. 2010;13:67-77

10. Sandalcioglu IE, Hunold A, Muller O, Bassiouni H, Stolke D, Asgari S. Spinal meningiomas: critical review of 131 surgically treated patients. Eur Spine J. 2008;17:1035-1041

11. Hirano K, Imagama S, Sato K, Kato F, Yukawa Y, Yoshihara H, 
Kamiya M, Deguchi M, Kanemura T, Matsubara Y, Inoh H. Primary spinal cord tumors: review of 678 surgically treated patients in Japan. A multicenter study. European spine journal. 2012 Oct 1;21(10):2019-26.

12. Preston-Martin S. Descriptive epidemiology of primary tumors of the spinal cord and spinal meninges in Los Angeles County, 1972-1985. Neuroepidemiology. 1990;9:106-111

13. Suh YL, Koo H, Kim TS, Chi JG, Park SH, Khang SK, Choe G, Lee MC, Hong EK, Sohn YK, Chae YS, Kim DS, Huh GY, Lee SS, Lee YS. Tumors of the central nervous system in Korea-a multicenter study of 3221 cases. J Neurooncol. 2002;56:251-259
14. Chamberlain MC, Tredway TL. Adult primary intradural spinal cord tumors: a review. Current neurology and neuroscience reports. 2011;11(3):320-8

15. Shrivastava RK, Epstein FJ, Perin NI, Post KD, Jallo GI. Intramedullary spinal cord tumors in patients older than 50 years of age: management and outcome analysis. Journal of Neurosurgery: Spine. 2005;2(3):249-55

16. Watanabe M, Sakai D, Yamamoto Y, Iwashina T, Sato M, Mochida J. Upper cervical spinal cord tumors: review of 13 cases. Journal ofOrthopaedic Science. 2009;14(2):175-81 